\section{Exploring the use of strategic frameworks in dental practice}

\author{
S. Willcocks ${ }^{1}$
}
IN BRIEF
- Raises awareness of the importance of strategy for NHS and private practices.
- Gives emphasis to the importance of assessing and responding to the 'industry context' or environment and changes in government policy.
- Explores two possible strategic frameworks that might be useful for this purpose and help to guide the future direction of a practice.

This paper explores the use of strategic frameworks in NHS and private dental practice. It reviews the policy context of dentistry and suggests the challenges in this context will require dental practices to prioritise understanding and engagement with a strategic approach. A strategic approach will be required in order to enhance and improve performance. Two specific strategic frameworks will be explored in terms of their relevance to NHS and private dental practice.

Strategy is an academic subject with a long history and a variety of competing theories and perspectives. ${ }^{1}$ This has led to a diversity of strategic typologies or frameworks. ${ }^{2}$ Two such frameworks will be explored in this paper - the first associated with the ideas of Michael Porter, and the second with Miles, Snow and colleagues. These will be used to provide insight into strategy-making in both NHS and private dental practice.

The frameworks offer an 'outside in' perspective on strategy; that is, strategy, or the future direction of an organisation, is influenced by external factors in the environment. ${ }^{3}$ A key feature of an 'outside in' perspective is the process by which an organisation adjusts, or adapts its strategy in response to external factors such as competitors or the market, or government policy context. ${ }^{3}$

\section{POLICY CONTEXT}

The policy context for dentistry is a diverse mix of public, private and growing corporate dental sectors. It is currently undergoing considerable change. In the NHS, policy reforms have emphasised patient involvement, clinically-led commissioning and quality. New organisations have been created to deliver these objectives, in particular a new commissioning organisation, NHS England. The latter is important for dentistry given its responsibility for planning, and

'Lancashire Business School, University of Central Lancashire, Greenbank Building, Preston, PR1 2HE Correspondence to: Dr Steve Willcocks

Email:SGWillcocks@uclan.ac.uk

\section{Refereed Paper}

Accepted 16 January 2015

DOI: 10.1038/sj.bdj.2015.94

${ }^{\circledR}$ British Dental Journal 2015; 218: 219-221 commissioning of primary and secondary care dental services, and for holding NHS dental contracts. NHS England has created area teams to replace Primary Care Trusts (PCTs), the role of which is to plan and secure all dental services, ensure value for money, facilitate innovation, deliver return on investment and support optimum delivery of services. ${ }^{4}$ Local professional networks have been established to provide clinical advice to commissioners, and promote innovation and best practice in dentistry. New models of care are being promoted such as multi-speciality community providers and vertically integrated primary and acute care systems, although no specific mention is made of dentistry in these new models. ${ }^{5}$

In addition to organisational changes, a new dental contract is being piloted with the intention of correcting the perceived anomalies of the dental contract introduced in 2006. New systems of remuneration are being tested alongside the contract. Dental practices face the uncertainty of various changes, such as a greater focus on quality, clinical outcomes, improvements to oral health, access, prevention and less emphasis on dental activity. The challenges faced by dental practices might include coping with the pace of change; dealing with structural change, turning round or leading organisations out of failure; leading innovation and change and developing leadership. ${ }^{6}$ Significant management and leadership expertise will be required to deal with these changes. Success in dealing with change may be particularly dependent on expertise in strategic decision making. ${ }^{7}$

In this context, it is important that dental practices, in the NHS or private sector, are clear about their strategy and the choices available to guide the future direction of the practice. Strategy will need to focus on ways of improving performance. Performance improvement is high on the agenda for many countries, not just the UK. ${ }^{8}$

This paper will look at two well-known strategic frameworks. While not new, they offer a way of conceptualising strategy and improving performance in NHS and private dental practice. The first framework is that associated with Michael Porter, based on his work with US organisations. ${ }^{9}$

\section{GENERIC STRATEGIES}

Porter advises that strategy begins with analysis of the 'industry' context, or environment, using competitor analysis. The latter is represented as five forces or threats emanating from this context: (i) threat of new entrants; (ii) threat of substitute service; (iii) threat of rivalry among existing competitors; (iv) threat or bargaining power of buyers; (v) bargaining power of suppliers. This framework may be used by dental practices to analyse different external threats in the environment, and devise ways of dealing with them, for example, by adopting generic strategies. ${ }^{9}$

The first force or threat is the extent to which a dental practice is threatened by the entry of new dental practices. This may depend on barriers to entry such as how difficult it is to set up a new dental practice. It is possible to enter private dentistry although a barrier may be capital costs to set up a new practice. In the case of NHS dentistry, it has been suggested that so far the existing dental contract has been a barrier to entry, ${ }^{10}$ and it remains to be seen whether this will change with the new contract. Similarly, the second potential threat is from a substitute service, 
for example, this could be by other dental professionals taking over part of the dentist's role, or the threat of substitute services provided by alternative providers. ${ }^{11}$ Likewise, a third threat is the possibility of rivalry between dental practices, particularly where they are numerous and the services they provide lack differentiation. Rivalry may exist in private dentistry but it also depends on industry growth and strength of the 'brand' identity, for example, practices establishing a name in cosmetic dentistry. ${ }^{12}$ In the NHS, this depends on policy changes such as the new contract, new quality measures and the dental quality and outcomes framework (DQOF). The fourth force or threat relates to the bargaining power of buyers. In NHS dentistry, the 'buyer' is NHS England, in private dentistry it might be public or private insurers. If they are of sufficient size, buyers are likely to represent a significant threat to, or influence on, a dental practice. The relative power balance between provider and commissioner is a long standing issue. It can be argued that the new commissioning arrangements give more power to the 'buyer' in the NHS. NHS England is effectively a single national buyer. Such arrangements may be stronger from the buyers' point of view than the previous system of local 'buyers', the PCTs. The final force or threat is the bargaining power of suppliers. These may be the supplier of drugs, equipment, materials and so forth, and these may also be a potential strategic threat to dental practices, particularly if suppliers are few in number, or dominated by one supplier.

These threats emanate from the dental 'industry' context or environment, and may impact on the performance of individual dental practices. Porter suggests that organisations adopt one of three generic strategies or positions in order to respond to these external challenges. ${ }^{9}$ These are a differentiation strategy, a cost leadership strategy and a 'niche' strategy.

A differentiation strategy focuses on a dental practice competing, defending, or responding to external threats on grounds of high quality or perceived differentiation from other practices. This may be associated with establishing a 'brand' or name, and may act as a barrier to entry, or way of dealing with rivalry from other practices. Competing on quality means the service has to justify the potentially high price by being recognised in some way for being different or unique, for example, by clinical excellence, expertise, service provision, delivery, or 'customer'/patient feedback. In other words, it needs to be clearly differentiated from other practices. Competing on quality and price may be of obvious concern to private dentistry. The NHS is currently committed to a fixed price system in the 2006 contract. However, there will be a requirement to address quality in the DQOF. The new contract may reward practices on the basis of their relative performance in the latter. So a differentiation strategy may be appropriate in both NHS and private sectors, although constrained by price in the former.

Alternatively, pursuing a cost leadership strategy will focus dental practice strategy on efficiency, and low costs. Dental practices working with NHS contracts may be required to target efficiency and productivity savings, reduce management costs, whilst at the same time adhere to prescribed standards of quality. Again, these may help a practice to deal with the perceived threat of a buyer, such as NHS England or insurer, and demands for cost savings. A cost leadership strategy assumes high volume, and low cost, in contrast with a differentiation strategy which assumes low volume, and high cost. It can be debated whether the former has applied to the NHS and the latter to private dentistry. This strategy may be particularly appropriate in the current NHS context, where cost containment is important.

A generic strategy is essentially one of the above, applied to a 'niche' market or segment. Similar to the analyser strategy below, this is, to some extent, a middle range strategy, in that it allows a dental practice to experiment in a particular part of the market but without the same risks as the above. This may be used in a limited way in both NHS and private sectors.

The second strategic framework is provided by Miles, Snow and colleagues, based on their work in public and private sector organisations, including healthcare organisations. ${ }^{13}$ As will be seen, there are some similarities with Porter's generic strategies, so the second framework may be seen as complimentary to, or an alternative to, the ideas of Porter.

\section{TYPOLOGY OF STRATEGIES}

Like Porter, Miles, et al., state that strategy is about the "dynamic process of adjusting to environmental change and uncertainty'. ${ }^{13}$ Thus, dental practices need to be innovative in achieving successful adjustment. They suggest this dynamic process takes place in an adaptive cycle of decision making, in which organisations make decisions in three interrelated domains. ${ }^{13}$ Firstly, entrepreneurial decisions are made about the strategy, for example, by the owner of the practice; then 'engineering' or operational decisions are made about how to deliver the service, consistent with the strategy; and thirdly, administrative decisions are made about the appropriateness of supporting roles, relationships, and processes. ${ }^{13,14}$ Organisations have a choice from four possible strategic typologies or positions, depending on the type of environment the organisation operates in: a 'defender' strategy, 'prospector' strategy, 'analyser' strategy and 'reactor' strategy. ${ }^{13}$

Adopting a 'defender' strategy means a dental practice's main strategy is to defend against competitors or external challenges by means of efficiency, that is, by being more efficient than other practices in service delivery and cost control. It is a strategy suitable for those in a relatively stable environment with reliance on technology as a means of enhancing control. ${ }^{13}$ It is similar to Porter's cost leadership strategy. Efficiency and reduced costs are targets in the Government's dental contract up lift for 2014/15. Organisations with expertise in defending may be better placed to cope in an environment where cuts, efficiency savings, and protecting services are important. ${ }^{8}$ Defending means making the right 'engineering' and administrative decisions, ensuring strategy, structure and processes are designed with priority given to how the service is delivered to the patient, with emphasis on operational efficiency. Thus, 'defending' may be obvious strategy for a dental practice in the current challenging NHS environment.

Alternatively, adopting a 'prospector' strategy or position requires a dental practice to identify new markets or services, or the provision of services in new settings. In other words, the organisation is innovative and may be a pioneer in developing new services. ${ }^{15}$ This may be by diversifying into new markets geographically, or by offering new dental services to the existing or new patient base. The new dental contract currently being piloted allows for scope to earn more by taking on more patients, so attracting and retaining patients may be important. It may also incentivise access. With regard to new services, in the NHS, this may involve more emphasis on preventative services and health education, with perhaps less emphasis on treatment. Adopting a prospector strategy is associated with high levels of performance. ${ }^{8}$ This strategy is appropriate in a dynamic environment where growth is required and allowed or funded by commissioners.

Adopting an 'analyser' strategy combines the above strategies, and enables a dental practice to defend against competition, respond to financial pressure, and at the same time, exploit the potential of new developments or new market. The intended outcome is a practice which is structured in a way that enables it to defend itself - such as utilising operational management techniques 
geared to efficiency - but with the capability to foster innovation and identify new opportunities. This may be an 'ideal type' for a dental practice operating in a complex environment, given the need for both cost containment and future service development.

The fourth typology is characterised as a reactive strategy for dental practices, and is not really a strategy, although organisations working in the NHS have a history of reacting to government policy. Reactive strategy is where an organisation has not successfully adjusted to environmental change: 'if a business lacks insight or if it fails to take advantage of alignment opportunities afforded by the adaptive cycle, it will be an incongruent, poorly performing reactor. ${ }^{14}$ As such, the outcome of this strategy is that a dental practice is not aligned with its environment, pursuing a strategy that is inappropriate in the context of the current climate, or failing to capitalise on new opportunities. An example of this might be where a dental practice is not sufficiently addressing patient or commissioning needs or is not prioritising the right clinical or organisational objectives.

There is a mixed view about the value of each typology, although it is contended that prospectors, defenders, and analysers perform better than reactors. ${ }^{15}$ The same authors report that "the defender strategy is the most effective for the primary mission of the organisation and that the prospector and reactor strategies work best in regard to the goals of the more politically powerful elements of the organisation's environment'. ${ }^{15}$ Boyne and Walker believe that prospector strategies are associated with higher levels of performance and such strategies are "best able to overcome performance obstacles associated with regulation and red tape. ${ }^{8}$

\section{CONCLUSION}

The ability to understand and engage with strategy is important when determining whether the practice works with an NHS contract, private dentistry or both, given the changing context outlined earlier. In the NHS, the policy changes underway nationally will require dental practices to become more strategic, and adaptive to these changes. This will mean more emphasis on being innovative, for example, working in dental care pathways, prioritising patient outcomes, quality, and effectiveness, addressing changes in patient needs and providing greater access to services. In private dentistry, strategy is a way of ensuring that practices are aware of, and respond appropriately to, their patients and competitors, and the market.

Practices can adopt the above generic frameworks as a way of responding to policy changes and external pressures and bringing about successful alignment with the environment. Both the typology of strategies and Porter's generic strategies imply that strategy is an 'outside in' process. They offer a way of understanding strategy in relation to the challenges in the outer context, particularly in identifying ways of dealing with these challenges, and deciding on the content of strategy. Porter's contribution is a framework for analysing the 'industry' context, and a choice of three generic strategies. Miles et al. offer a variation on this with their typology of strategies, and adaptive decision making model. Intended outcomes associated with this approach may be improved performance, effectiveness, and efficiency for dental practices; although it must be noted that generic frameworks are only a starting point for further development and more specific consideration of strategy.
An 'outside in' approach to strategy has been implicitly endorsed by the BDA: 'to succeed, a dental practice needs direction and plans for future development that are continually reviewed and adapted to changing circumstances and outside influences. ${ }^{16}$

1. Pettigrew $A$, Thomas $H$, Whittington R. Handbook of strategy and management. London: Sage, 2006.

2. Moussetis R. Ansoff revisited: how Ansoff interfaces with both the planning and learning schools of thought in strategy. J Manag Hist 2011; 17: 102-125.

3. McKiernan P. Exploring environmental context within the history of strategic management. Int Stud Manag Organ 2006; 36: 7-21.

4. NHS Commissioning Board. Securing excellence in commissioning NHS dental services. 2013. Online information available at http://www.england.nhs. uk/wp-content/uploads/2013/02/commissioningdental.pdf (accessed January 2015).

5. NHS England. Five year forward view. 2014. Online information available at http://www.england.nhs.uk/ ourwork/futurenhs/ (accessed January 2015).

6. Hartley J, Benington J. Leadership for healthcare. Bristol: Policy Press, 2010.

7. Parayitam S, Dooley R S. Is too much cognitive conflict in strategic decision making teams too bad? Int J Confl Manag 2011; 22: 342-357.

8. Boyne G A, Walker R M. Strategic management and public service performance: the way ahead. Public Admin Rev 2010; 70: s1: a185-s192.

9. Porter M E. How competitive forces shape strategy. Harv Bus Rev 1979; 57: 137-145.

10. Office of Fair Trading. Report into the dental market 2012. Online information available at http://webarchive.nationalarchives.gov.uk/20140402142426/ http:/www.oft.gov.uk/shared_oft/market-studies/ Dentistry/OFT1414.pdf (accessed January 2015).

11. Hudson R. (2010). Marketing situation analysis and strategic planning for NHS clinical services. J Manag Marketing Healthc 2010; 3: 224-238.

12. Macmillan H, Tampoe M. Strategic management. Oxford: Oxford University Press, 2000.

13. De Wit B, Meyer R, Huygens M. Strategy, process, content context, - an international perspective. Minnesota: West Publishing Company, 1994.

14. Hambrick D C. On the staying power of defenders analysers and prospectors. Academy Manag Exec 2003; 17: 115-118.

15. Meier K J, O'Toole L J, Boyne G A, Walker R M. Strategic management and the performance of public organisations: testing venerable ideas against recent theories. J Public Adm ResTheory 2006; 17: 357-377.

16. BDA, (2014)., Managing your Business, B D A, London. http://dev.bda.building-blocks.com/dentists/ advice/ba/bm.aspx 